\title{
Effect of facemask ventilation with different ventilating volumes on gastric insufflation during anesthesia induction in patients undergoing laparoscopic cholecystectomy
}

\author{
Wu Tianliang, MBBS, MD, Shao Gang, MBBS, Yu Guocan, MBBS, Fang Haixing, MBBS.
}

\begin{abstract}

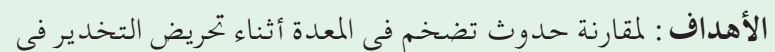

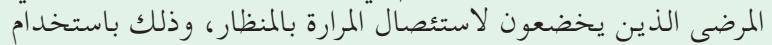

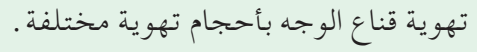

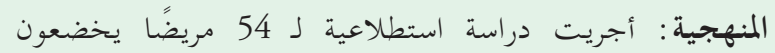

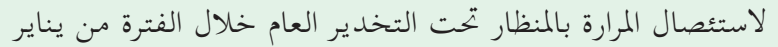

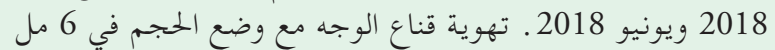

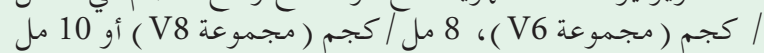

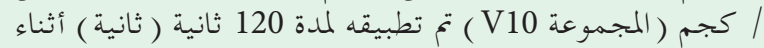

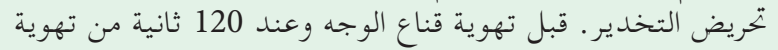

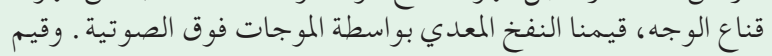

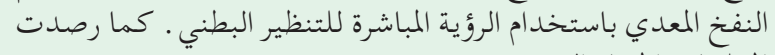

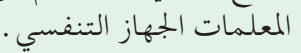

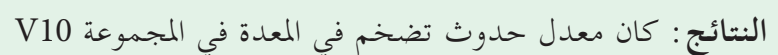

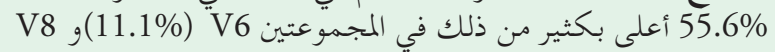

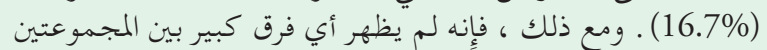

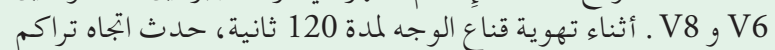

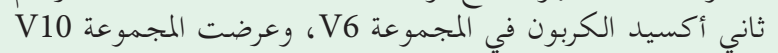

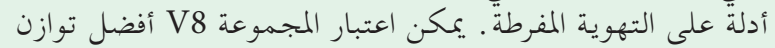
بين انخفاض نفخ المعدة والتهوية الفعالة في الرئة .

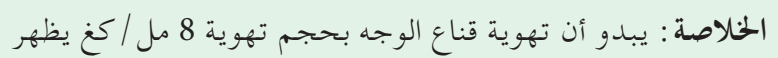

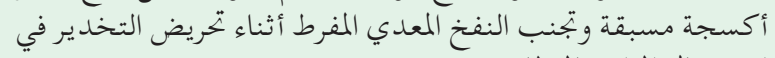

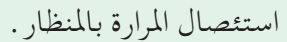

Objectives: To compare the occurrence of gastric insufflation during anesthesia induction in patients undergoing laparoscopic cholecystectomy, using facemask ventilation with different ventilation volumes.

Methods: This is a prospective study of 54 patients undergoing laparoscopic cholecystectomy under general anesthesia between January 2018 and June 2018. Facemask ventilation with volume mode controlled at $6 \mathrm{ml} / \mathrm{kg}$ (group V6), $8 \mathrm{ml} / \mathrm{kg}$ (group V8) or $10 \mathrm{ml} / \mathrm{kg}$ (group V10) was applied for 120 seconds (sec) during anesthesia induction. Before facemask ventilation and at $120 \mathrm{sec}$ of facemask ventilation, gastric insufflation was determined by ultrasonography. Gastric insufflation was also evaluated using direct vision of laparoscopy. Respiratory parameters were monitored.

Results: The incidence of gastric insufflation in group V10 (55.6\%) was significantly higher than that in groups V6 (11.1\%) and V8 (16.7\%). However, it showed no significant difference between groups V6 and V8. During facemask ventilation for $120 \mathrm{sec}$, carbon dioxide accumulation trend occurred in group V6, and group V10 exhibited evidence of hyperventilation. Group V8 might be considered the best balance between low gastric insufflation and effective lung ventilation.

Conclusion: Facemask ventilation with a ventilation volume of $8 \mathrm{ml} / \mathrm{kg}$ seems to have adequate preoxygenation and avoid excessive gastric insufflation during anesthesia induction in laparoscopic cholecystectomy.

Saudi Med J 2019; Vol. 40 (10): 989-995 doi: 10.15537/smj.2019.10.24306

From the Department of Anesthesiology (Wu, Shao, Yu), and from the Department of Hepatobiliary Surgery (Fang), First People's Hospital of Fuyang District, Hangzhou, China.

Received 15th June 2019. Accepted 2nd September 2019.

Address correspondence and reprint request to: Dr. Tianliang Wu, Department of Anesthesiology, First People's Hospital of Fuyang District, Hangzhou, China.E-mail:277702427@qq.com

ORCID ID: https://orcid.org/0000-0001-7574-0124 
A good visual field is crucial for successful laparoscopic cholecystectomy. However, there is a high risk of gastric insufflation during anesthesia induction with facemask ventilation. This impair the surgical visual field, which sometimes require emptying the stomach using a gastric tube. In patients with general anesthesia, gastric insufflation can cause various complications ${ }^{1-3}$ such as stomach perforation, gastric content regurgitation, nausea, vomiting, and aspiration pneumonitis, leading to increased risk of mortality.

Different ventilation modes during anesthesia induction can cause different degrees of gastric insufflation, ${ }^{4-7}$ but there are few reports of the relationship between gastric insufflation and volumecontrolled facemask ventilation during anesthesia induction. Over the past years, some studies have found that ultrasonography can accurately assess the volume and properties of gastric contents. ${ }^{8-10}$ Bouvet et $\mathrm{al}^{11}$ reported a significant correlation between antral area and gastric volume measured by ultrasonography. Therefore, we selected the antral area measured by ultrasonography to calculate gastric volume.

In the present study, ultrasonography was used to detect the effect of facemask ventilation with different ventilation volumes on gastric insufflation. Our study was performed on patients undergoing laparoscopic cholecystectomy during general anesthesia induction, so as to provide reference for clinical anesthesia operation.

Methods. Prior related study was searched in PubMed using keywords such as facemask ventilation, anesthesia induction, gastric insufflation, and laparoscopic cholecystectomy. This is a prospective study of 54 patients (29 males and 25 females) undergoing elective laparoscopic cholecystectomy under general anesthesia between January 2018 and June 2018 in the Department of Anesthesia, Fuyang District First People's Hospital, Hangzhou, China. Our study was approved by the Ethics Committee of Fuyang District First People's Hospital and followed the principles of the Declaration of Helsinki. Informed consent was obtained from the patients.

The age range was 29-84 years. American Society of Anesthesiologists physical status was I-II. The exclusion criteria were gastroparesis, gastrectomy,

Disclosure. This study was funded by the Agricultural and Social Development Scientific Research Library Project of Hangzhou, China (Grant No. 20171226Y171). gastroesophageal regurgitation, upper respiratory tract infection, potentially difficult airway, allergy to muscle relaxant, hypertension, diabetes mellitus, obesity, and an unclear ultrasound image under gastric ultrasonography before anesthesia induction. The patients were randomly divided into 3 groups using a random table $(n=18)$ : Tidal volume $(\mathrm{VT})=6 \mathrm{ml} / \mathrm{kg}$ (group V6), VT=8 ml/kg (group V8) and VT=10 ml/kg (group V10). Patients in the 3 groups were further divided into 2 subgroups, GI+ and $\mathrm{GI}^{-}$, according to the presence or absence of gastric insufflation.

Anesthesia induction. Intravenous access to an upper arm was established. Routine electrocardiography, oxygen saturation $\left(\mathrm{SpO}_{2}\right)$ and noninvasive blood pressure monitoring were performed after entering the operation room. Midazolam $0.05 \mathrm{mg} / \mathrm{kg}$ (Enhua Pharmaceuticals, Jiangsu, China) was provided intravenously. Facemask oxygen inhalation was $3 \mathrm{~L} / \mathrm{min}$. Sufentanil citrate (Renfu Pharmaceuticals, Yichang, China) $0.5 \mu \mathrm{g} / \mathrm{kg}$, propofol (AstraZeneca, China) $1.8 \mathrm{mg} / \mathrm{kg}$ and rocuronium (Xianju Pharmaceuticals, Zhejiang, China) $0.6 \mathrm{mg} /$ $\mathrm{kg}$ were intravenously administered for anesthesia induction.

An oropharyngeal airway was placed when the patient's eyelash reflex disappeared by the same anesthesiologist with 5 years of experience. A facemask suitably sized for the patient was applied to ensure full sealing. Facemask ventilation was then started for 120 seconds (sec) with a Datex Ohmeda S/5 Avance anesthetic machine (Ohmeda, USA) at oxygen flow $3 \mathrm{~L} /$ min, inspired oxygen concentration $100 \%$, respiratory rate $15 / \mathrm{min}$ and inspiratory/expiratory ratio $1: 2$. The ventilation volumes were set at VT $6 \mathrm{ml} / \mathrm{kg}$ (group V6), VT $8 \mathrm{ml} / \mathrm{kg}$ (group V8), or VT $10 \mathrm{ml} / \mathrm{kg}$ (group V10).

The VT was set by a nurse and the numbers on the anesthetic machine was covered using an opaque paper. The anesthesiologists and surgeons were blinded to patient grouping.

Ultrasonography. Before facemask ventilation after anesthesia induction, and at $120 \mathrm{sec}$ of facemask ventilation, a portable ultrasound locator (Acuson Sequoia 512 color Doppler ultrasonic apparatus with a $3.5 \mathrm{MHz}$ ultrasonic probe) was used to scan the sagittal plane under the xiphoid process. ${ }^{11}$ The section image was adjusted to include the antrum, sagittal plane of abdominal aorta, left lobe of liver, and superior mesenteric artery. The anteroposterior diameters (D1) of the antrum and superoinferior (D2) of the antrum were measured 3 times to obtain a mean value (Figure 1 ). The cross-sectional antral area was calculated using the formula: antral area $=\pi^{*} \mathrm{D} 1^{*} \mathrm{D} 2 / 4$. If there was a comet-tail sign or antral area enlargement, a positive 


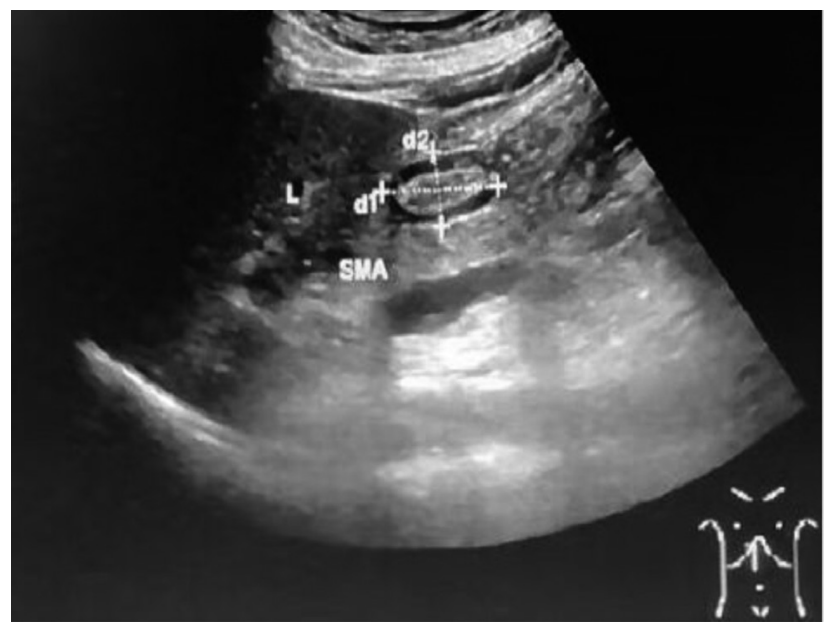

Figure 1 - Gastric ultrasonographic image during induction of anesthesia. The anteroposterior diameter (D1) and the superoinferior diameter (D2) of the antrum were measured. L - liver, SMA superior mesenteric artery.

gastric insufflation was recorded. ${ }^{11}$ After the first ultrasonic measurement, the position of the ultrasonic probe was marked, and the measurements were repeated before facemask ventilation after anesthesia induction and at $120 \mathrm{sec}$ of facemask ventilation at the mark. Endotracheal intubation began at $120 \mathrm{sec}$ of facemask ventilation. Sevoflurane $3 \%$ was used to maintain anesthesia during surgery.

Intraoperative evaluation. After sterilizing and laying towel, the surgeon performed laparoscopic cholecystectomy with 3 ports. After placing the laparoscope in the abdominal cavity, the degree of gastric distension was evaluated by the surgeon with a gastric distension score: grade one, the stomach was unfilled, there was no tension within it and the lesser curvature did not enter into the gallbladder area; grade 2 , the stomach was filled a little, there was low tension within it and the lesser curvature partly entered into the gallbladder area; grade 3, the stomach was moderately filled, there was high tension within it, the lesser curvature covered completely the gallbladder area, but the surgical visual field could be exposed with a laparoscopic brace for difficult completion of the surgery; grade 4, the stomach was extremely distended, there was extremely high tension within it, the lesser curvature covered completely the whole gallbladder area, it was difficult to expose the surgical visual field with a laparoscopic brace, and it was necessary to place a gastric tube to expel gas and reveal the surgical visual field before the surgery could be completed. In our study as we defined grade one or 2 of gastric distension was an excellent exposure of the hepatobiliary triangle.
The pressure of carbon dioxide pneumoperitoneum was maintained at 11-17 $\mathrm{mmHg}$.

Respiratory parameters. Oxygen saturation was recorded at $30 \mathrm{sec}$, real-time peak inspiratory pressure (PIP) was recorded at $60 \mathrm{sec}$, end-tidal carbon dioxide partial pressure $\left(\mathrm{PetCO}_{2}\right)$ was recorded at $90 \mathrm{sec}$, and end-tidal oxygen concentration $\left(\mathrm{ETO}_{2}\right)$ was recorded at $120 \mathrm{sec}$ of facemask ventilation.

Statistical analysis. In our pre-trial, a $12 \mathrm{ml} / \mathrm{kg}$ (group V12) and $14 \mathrm{ml} / \mathrm{kg}$ (group V14) were included and 10 adult patients in each group were pre-tested. The incidences of gastric insufflation in each group were $10 \%$ (group V6), 20\% (group V8), 40\% (group V10), $40 \%$ (group V12), and 60\% (group V14). According to the Cochran-Armitage trend test, the patients in each group were set up with the same configuration. With an effectiveness of 0.9 , the continuous correction of bilateral $\mathrm{Z}$ test was performed, resulting in 16 patients for each group (accurate test efficiency 0.91). Assuming a drop-out rate of $10 \%$, there should be 18 patients for each group. The average PIP in group $\mathrm{V} 12$ was $22 \mathrm{cmH}_{2} \mathrm{O}\left(1 \mathrm{cmH}_{2} \mathrm{O}=0.098 \mathrm{kPa}\right)$ during anesthesia induction, which was much higher than $15 \mathrm{cmH}_{2} \mathrm{O}^{11}$ when low gastric insufflation rate and effective pulmonary ventilation were both possible. The mean PIP in group V14 was $25 \mathrm{cmH}_{2} \mathrm{O}$ with a higher gastric insufflation rate, so neither group was included in our study. Therefore, the total sample of the remaining 3 groups were 54 patients with 18 patients in each group.

Quantitative data were expressed as mean and standard deviation. The ANOVA test was used for multi-group comparison followed by the least significant difference (LSD) test for pairwise comparison. The paired t-test was used for intra-group comparison. Comparison of $\mathrm{PetCO}_{2}, \mathrm{ETO}_{2}$ and PIP at $30 \mathrm{sec}$, $60 \mathrm{sec}, 90 \mathrm{sec}$, and $120 \mathrm{sec}$ of facemask ventilation in the 3 groups were made using the 2-way ANOVA test. Qualitative data were expressed by constituent ratio or rate and analyzed using the Chi-square test was used for comparison between groups. The rank sum test was used for comparison between groups for grade of treatment. All statistical analyses were performed using the Statistical Package for Social Sciences version 21.0 (IBM Corp, Armonk, NY, USA). A $p<0.05$ was considered statistically significant.

Results. There was no significant difference in the general data between the 3 groups $(p>0.05$, Table 1$)$. No patients were excluded due to unclear imaging of the antral area by ultrasonography either before facemask ventilation after induction or at $120 \mathrm{sec}$ of 
mask ventilation. In no patient relevant air leak during facemask ventilation was found. No gastric distension was found visually by the surgeons in patients without gastric insufflation assessed by ultrasonography. The number of patients (0,2, and 4) with gastric insufflation visually found by the surgeons, correlated with gastric distension measured by ultrasonography in groups V6, V8 and V10. However, no patient required gastrointestinal decompression for excessive gastric distension. Gastric distension during surgery were graded as grade one in 18 patients in group V6, grade one in 16 patients and grade 2 in 2 patients in group $\mathrm{V} 8$, grade one in 14 patients, and grade 2 in 4 patients in group V10. The excellent and good rates were $100 \%$. During anesthesia induction, $\mathrm{SpO}_{2}$ was equal to or greater than $99 \%$ in all 3 groups.

The incidence of gastric insufflation in group V10 was significantly higher than that in groups V6 and V8; but the difference between groups V6 and V8 was not statistically significant (Table 2). Compared with the antral area before facemask ventilation after anesthesia induction, the antral area in groups V6 and group V8 at $120 \mathrm{sec}$ of facemask ventilation was not significantly changed, but the antral area in group V10 at $120 \mathrm{sec}$ of facemask ventilation was significantly increased. The antral area of the $\mathrm{GI}^{+}$subgroup in group V10 at $120 \mathrm{sec}$ of facemask ventilation was significantly higher than that before facemask ventilation after anesthesia induction, while that of the $\mathrm{GI}^{+}$and $\mathrm{GI}^{-}$subgroups in the groups V6 and V8 and that of the $\mathrm{GI}^{-}$subgroup in group V10 were not significantly changed compared with that before facemask ventilation after anesthesia induction (Table 3).

End-tidal carbon dioxide partial pressure was higher in group V6 than that in groups V8 and V10 and lower in group V10 than that in group V8 at $30 \mathrm{sec}, 60 \mathrm{sec}$, $90 \mathrm{sec}$ and $120 \mathrm{sec}$ of facemask ventilation. End-tidal carbon dioxide partial pressure was higher in group V6 and lower in group V10 at $60 \mathrm{sec}, 90 \mathrm{sec}$ and $120 \mathrm{sec}$ compared with $30 \mathrm{sec}$, higher in group V6 and lower in group V10 at $90 \mathrm{sec}$ and $120 \mathrm{sec}$ compared with 60 $\mathrm{sec}$, and higher in group V6 and lower in group V10 at $120 \mathrm{sec}$ compared with $90 \mathrm{sec}$. End-tidal oxygen concentration was lower in group V6 than that in the V8 and V10 group and higher in group V10 than that in group V8 at $30 \mathrm{sec}, 60 \mathrm{sec}, 90 \mathrm{sec}$, and $120 \mathrm{sec}$. End-tidal oxygen concentration was higher in 3 groups at $60 \mathrm{sec}, 90 \mathrm{sec}$ and $120 \mathrm{sec}$ compared with $30 \mathrm{sec}$, higher in 3 groups at $90 \mathrm{sec}$, and $120 \mathrm{sec}$ compared with $60 \mathrm{sec}$, and higher in 3 groups at $120 \mathrm{sec}$ compared with 90 sec. Peak inspiratory pressure was lower in group V6
Table 1 - Comparison of general data between the 3 groups.

\begin{tabular}{lccccc}
\hline Group & n & Age, year & Male & Female & BMI, $\mathbf{~ g g} / \mathrm{m}^{2}$ \\
\hline V6 & 18 & $45.4 \pm 9.3$ & 12 & 6 & $22.4 \pm 2.5$ \\
V8 & 18 & $44.9 \pm 10.0$ & 9 & 9 & $23.0 \pm 1.2$ \\
V10 & 18 & $42.7 \pm 8.7$ & 8 & 10 & $21.0 \pm 1.7$ \\
-value & 0.636 & 0.38 & 0.148 \\
\hline \multicolumn{5}{c}{ Data are expressed as mean \pm standard deviation or frequencies. } \\
V6 - facemask ventilation with volume mode controlled at $6 \mathrm{ml} / \mathrm{kg}$, \\
V8 - facemask ventilation with volume mode controlled at $8 \mathrm{ml} / \mathrm{kg}$, \\
V10 - facemask ventilation with volume mode controlled at $10 \mathrm{ml} / \mathrm{kg}$, \\
\multicolumn{5}{c}{ BMI - body mass index } \\
\hline
\end{tabular}

Table 2 - Comparison of incidences of gastric insufflation during anesthesia induction between the 3 groups.

\begin{tabular}{lccc}
\hline Group & $\mathbf{n}$ & $\begin{array}{r}\text { Gastric insufflation } \\
\mathbf{n}(\%)\end{array}$ & $P$-value \\
\hline V6 & 18 & $2(11.1)$ & 0.005 \\
V8 & 18 & $3(16.7)$ & \\
V10 & 18 & $10(55.6)^{*}$ & \\
\hline
\end{tabular}

\begin{tabular}{c} 
Data are expressed as percentages or frequencies. V6 - facemask \\
ventilation with volume mode controlled at $6 \mathrm{ml} / \mathrm{kg}$, V8 - facemask \\
ventilation with volume mode controlled at $8 \mathrm{ml} / \mathrm{kg}, \mathrm{V} 10$ - facemask \\
ventilation with volume mode controlled at $10 \mathrm{ml} / \mathrm{kg}$ \\
${ }^{*}-p<0.05$ versus group V6, $\dagger-p<0.05$ versus group V8 \\
\hline
\end{tabular}

than that in the V8 and V10 group and was higher in group V10 than that in group V8 at $30 \mathrm{sec}, 60 \mathrm{sec}$, $90 \mathrm{sec}$, and $120 \mathrm{sec}$ (Table 4).

Discussion. Our study found that facemask ventilation with a ventilation volume of $10 \mathrm{ml} / \mathrm{kg}$ had a significantly higher incidence of gastric insufflation than 6 or $8 \mathrm{ml} / \mathrm{kg}$ during induction of anesthesia in laparoscopic cholecystectomy. Facemask ventilation with a ventilation volume of $8 \mathrm{ml} / \mathrm{kg}$ seems to have generally better respiratory parameters during the $120 \mathrm{sec}$ of anesthesia induction than the other 2 ventilation volumes.

During general anesthesia induction, apart from hand-controlled ventilation, pressure-controlled and volume-controlled ventilation are the most commonly used ventilation modes. ${ }^{12,13}$ In our study, volumecontrolled ventilation mode was used. Laparoscopic cholecystectomy is technically sensitive to the degree of gastric insufflation; thus, its prevention is critically important. In our study, higher ventilation volume was associated with higher PIP value, which reached $17 \mathrm{cmH}_{2} \mathrm{O}$ with the ventilation volume of $10 \mathrm{ml} / \mathrm{kg}$. The corresponding incidence of gastric insufflation was high as assessed by antral ultrasonography. However, the volume of insufflation did not adversely affect the 
Table 3 - Comparison of the antral area before and after facemask ventilation in the 3 groups.

\begin{tabular}{|c|c|c|c|c|}
\hline Group & $\mathrm{n}$ & $\begin{array}{l}\text { Antral area before facemask } \\
\text { ventilation, } \mathrm{mm}^{2}\end{array}$ & $\begin{array}{l}\text { Antral area after facemask } \\
\text { ventilation, } \mathrm{mm}^{2}\end{array}$ & $P$-value \\
\hline V6 & 18 & $394.5 \pm 55.6$ & $421.8 \pm 48.5$ & 0.140 \\
\hline $\mathrm{GI}^{+}$ & 2 & $387.5 \pm 13.1$ & $409.8 \pm 52.9$ & 0.716 \\
\hline $\mathrm{GI}^{-}$ & 16 & $395.4 \pm 59.0$ & $423.3 \pm 49.6$ & 0.172 \\
\hline V8 & 18 & $401.8 \pm 43.7$ & $425.2 \pm 43.9$ & 0.130 \\
\hline $\mathrm{GI}^{+}$ & 3 & $381.6 \pm 25.0$ & $436.6 \pm 41.0$ & 0.273 \\
\hline $\mathrm{GI}^{-}$ & 15 & $405.8 \pm 46.1$ & $422.9 \pm 45.5$ & 0.308 \\
\hline V10 & 18 & $417.9 \pm 46.8$ & $503.9 \pm 112.1$ & 0.001 \\
\hline $\mathrm{GI}^{+}$ & 10 & $429.1 \pm 44.3$ & $573.6 \pm 97.3$ & $<0.001$ \\
\hline $\mathrm{GI}^{-}$ & 8 & $404.0 \pm 48.9$ & $416.8 \pm 52.3$ & 0.441 \\
\hline \multicolumn{5}{|c|}{$\begin{array}{l}\text { Data are expressed as mean } \pm \text { standard deviation. V6 - facemask ventilation with volume mode } \\
\text { controlled at } 6 \mathrm{ml} / \mathrm{kg} \text {, V8 - facemask ventilation with volume mode controlled at } 8 \mathrm{ml} / \mathrm{kg}, \mathrm{V} 10 \text { - } \\
\text { facemask ventilation with volume mode controlled at } 10 \mathrm{ml} / \mathrm{kg}, \\
\mathrm{GI}^{+} \text {- with gastric isufflation, } \mathrm{GI}^{-} \text {-without gastric isufflation }\end{array}$} \\
\hline
\end{tabular}

Table 4 - Comparison of end-tidal carbon dioxide partial pressure, end-tidal oxygen concentration, and peak inspiratory pressure at 30sec, $60 \mathrm{sec}, 90 \mathrm{sec}$, and $120 \mathrm{sec}$ of facemask ventilation in the 3 groups.

\begin{tabular}{|c|c|c|c|c|c|c|}
\hline Variables & Group & $\mathrm{n}$ & $\begin{array}{c}\text { Facemask ventilation } \\
30 \mathrm{sec}\end{array}$ & $\begin{array}{c}\text { Facemask } \\
\text { ventilation } 60 \mathrm{sec}\end{array}$ & $\begin{array}{l}\text { Facemask ventilation } \\
90 \mathrm{sec}\end{array}$ & $\begin{array}{c}\text { Facemask ventilation } \\
120 \mathrm{sec}\end{array}$ \\
\hline \multirow{4}{*}{$\begin{array}{l}\mathrm{PetCO}_{2} \\
\mathrm{mmHg}\end{array}$} & V6 & 18 & $36.5 \pm 1.3^{*}$ & $38.7 \pm 1.4^{\star}$ & $40.7 \pm 1.6^{* \$^{* *}}$ & $42.4 \pm 1.8^{* \S^{* * \dagger \dagger}}$ \\
\hline & V8 & 18 & $35.0 \pm 1.4$ & $35.4 \pm 1.6$ & $35.2 \pm 1.4$ & $35.5 \pm 1.6$ \\
\hline & V10 & 18 & $34.0 \pm 1.3^{\ddagger}$ & $32.4 \pm 1.8^{\ddagger \S}$ & $30.4 \pm 1.8^{\ddagger \S^{* *}}$ & $28.4 \pm 1.8^{\ddagger 5^{* *+\dagger}}$ \\
\hline & $p$-value ${ }^{\dagger}$ & & $<0.001$ & $<0.001$ & $<0.001$ & $<0.001$ \\
\hline \multirow{4}{*}{$\begin{array}{l}\mathrm{ET0}_{2} \\
\mathrm{mmHg}\end{array}$} & V6 & 18 & $78.3 \pm 1.6^{*}$ & $80.3 \pm 1.6^{\star \$}$ & $82.4 \pm 1.7^{* \$^{* *}}$ & $84.2 \pm 1.7^{+5 *+1+}$ \\
\hline & V8 & 18 & $84.2 \pm 1.3$ & $86.2 \pm 1.5^{\S}$ & $88.1 \pm 1.6^{6^{* *}}$ & $90.1 \pm 1.7^{5^{* *+\dagger} \dagger}$ \\
\hline & V10 & 18 & $86.3 \pm 1.2^{\ddagger}$ & $88.4 \pm 1.2^{\ddagger \S}$ & $90.4 \pm 1.2^{\ddagger 5^{* *}}$ & $92.4 \pm 1.2^{\ddagger 5^{* *+\dagger}}$ \\
\hline & $p$-value ${ }^{\dagger}$ & & $<0.001$ & $<0.001$ & $<0.001$ & $<0.001$ \\
\hline \multirow{4}{*}{$\begin{array}{l}\text { PIP, } \\
\mathrm{cmH}_{2} \mathrm{O}\end{array}$} & V6 & 18 & $11.9 \pm 0.9^{*}$ & $12.2 \pm 0.7^{*}$ & $11.9 \pm 0.7^{*}$ & $12.2 \pm 0.8^{*}$ \\
\hline & V8 & 18 & $15.2 \pm 0.8$ & $15.2 \pm 0.8$ & $15.3 \pm 0.8$ & $14.9 \pm 1.0$ \\
\hline & V10 & 18 & $17.0 \pm 0.5^{\ddagger}$ & $17.0 \pm 0.9^{\ddagger}$ & $17.3 \pm 0.8^{\ddagger}$ & $17.3 \pm 0.9^{\ddagger}$ \\
\hline & $p$-value ${ }^{\dagger}$ & & $<0.001$ & $<0.001$ & $<0.001$ & $<0.001$ \\
\hline \multicolumn{7}{|c|}{ 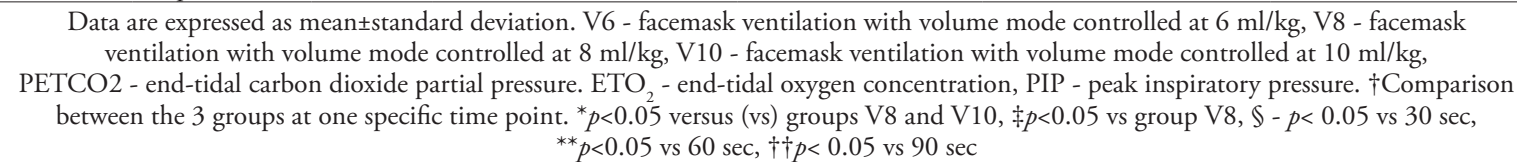 } \\
\hline
\end{tabular}

operation. In a previous study, ${ }^{11}$ the average ventilation volume was approximately $8 \mathrm{ml} / \mathrm{kg}$ when the PIP value was $15 \mathrm{cmH}_{2} \mathrm{O}$, which was consistent with the average PIP value of $15 \mathrm{cmH}_{2} \mathrm{O}$ in group V8 in our study.

In the present study, the antral area in group V10 at $120 \mathrm{sec}$ of facemask ventilation was significantly higher than that at $30 \mathrm{sec}$, which was mainly caused by the significant increase in the antral area in the $\mathrm{GI}^{+}$ subgroup of group V10. We speculated that facemask ventilation with a large ventilation volume was the direct cause of gastric insufflation in our patients during anesthesia induction. However, this ventilation volume did not cause severe gastric distension; therefore, gastric tube placement for decompression was unnecessary. The main reason for this was the oropharyngeal airway used in our study. ${ }^{14} \mathrm{~A}$ second reason was that the induction time of anesthesia was only $120 \mathrm{sec}$. In this short period of time, gastric insufflation might not cause gastric distension and impair the visual field.

Ventilation of the patients during anesthesia induction was assessed using ETO EetCO $_{2}$ and PIP. In our study, the first $30 \mathrm{sec}$ of facemask ventilation was the ventilation balance time eliminating the effect of initial facemask ventilation on chest wall compliance. In terms of gas exchange, although none of the patients in group V6 had a reduction in $\mathrm{SpO}_{2}$ during anesthesia induction, the $\mathrm{PetCO}_{2}$ value in group V6 at $120 \mathrm{sec}$ of facemask ventilation was significantly higher than that at 
the other time points. Therefore, the ventilation volume of $6 \mathrm{ml} / \mathrm{kg}$ had a tendency of hypoventilation. End-tidal carbon dioxide partial pressure in group V10 was 28 $\mathrm{mmHg}$ at $120 \mathrm{sec}$ of facemask ventilation, indicating hyperventilation. Peak inspiratory pressure at each time point in group V10 was also higher than that in the other 2 groups; thus, the incidence of gastric insufflation was higher in this group. In terms of oxygen supply and nitrogen removal, ETO ${ }_{2}$ was increased in all 3 groups, but $\mathrm{ETO}_{2}$ in group $\mathrm{V} 6$ was lower during the whole facemask ventilation (approximately 84 at $120 \mathrm{sec}$ ), indicating that its oxygen reserve was poor. Group V8 might be considered the best balance between low gastric insufflation rate and effective lung ventilation.

It has been reported that a ventilation volume less than $6 \mathrm{ml} / \mathrm{kg}$ for general anesthesia resulted in hypoventilation; ${ }^{3,15}$ therefore, the low limit of ventilation volume was set at $6 \mathrm{ml} / \mathrm{kg}$. Gastric insufflation greater than $5 \mathrm{ml}$ can be evaluated using a stethoscope placed on the epigastric area. ${ }^{8,9,11}$ This method is highly subjective, and its reliability is uncertain when the air enters the stomach at a slower rate. Therefore, we used ultrasonography and direct vision of laparoscopy for the first time to assess gastric insufflation. There were more patients with gastric insufflation determined by ultrasonography than that determined by direct vision. There may be several possible reasons for this discrepancy. First, the determination of gastric insufflation was at different times for ultrasonography and direct vision. Second, the intraabdominal pressure was increased, and gastrointestinal peristalsis was proceeded during carbon dioxide pneumoperitoneum, which may have promoted the entry of gastric contents to the duodenum. Third, ultrasonography may be more sensitive in detecting gastric insufflation than direct vision under laparoscopy.

Rocuronium is a non-depolarizing muscular relaxant and was used during anesthesia induction in our study. It can reduce the tension of the proximal esophageal sphincter and pharyngeal musculature; thus, facilitating facemask ventilation, but also increase the incidence of gastric insufflation. ${ }^{10,14,16}$ In order to prevent airway resistance caused by glossoptosis and to decrease air entry into the stomach during facemask ventilation, an oropharyngeal airway was placed before commencing facemask ventilation in our study.

Study limitations. First, the sample size was relatively small. Second, the ultrasonography was not performed by a professional ultrasonographer, which might resulted in data error. Third, this is a single-center study.

In conclusion, facemask ventilation with a ventilation volume of $8 \mathrm{ml} / \mathrm{kg}$ rather than 6 or $10 \mathrm{ml} / \mathrm{kg}$ seems to have adequate preoxygenation and a lower incidence of gastric insufflation during anesthesia induction in laparoscopic cholecystectomy. Further investigation with a larger sample size and other surgeries is needed for better optimization of facemask ventilation.

Acknowledgment. The authors gratefully acknowledge Dr. Huajie Zhao, radiologist, who reviewed the ultrasonography images.

\section{References}

1. Fung AM, Chan FS, Wong IY, Law S. Synchronous perforations of the oesophagus and stomach by air insufflation: an uncommon complication of endoscopic dilation. BMJ Case Rep 2016; 2016: bcr2016216375.

2. Ghabach MB, El Hajj EM, El Dib RD, Rkaiby JM, Matta MS, Helou MR. Ventilation of nonparalyzed patients under anesthesia with laryngeal mask airway, comparison of three modes of ventilation: volume controlled ventilation, pressure controlled ventilation, and pressure controlled ventilationvolume guarantee. Anesth Essays Res 2017; 11: 197-200.

3. Okuyama M, Kato S, Sato S, Okazaki J, Kitamura Y, Ishikawa $\mathrm{T}$, et al. Dynamic behaviour of the soft palate during nasal positive pressure ventilation under anaesthesia and paralysis: comparison between patients with and without obstructive sleep-disordered breathing. Br J Anaesth 2018; 120: 181-187.

4. Isono S, Eikermann M, Odaka T. Facemask ventilation during induction of anesthesia: how "gentle" is "gentle" enough? Anesthesiology 2014; 120: 263-265.

5. Hang L, Wei S, Zhenkai X, Shu W, Chen Y, Chen Z, et al. Optimal pressure for facemask ventilation during induction of general anesthesia in adult patients: real-time ultrasonographic measurement of antral cross-sectional area. Chinese Journal of Anesthesiology 2017; 37: 461-463.

6. Lee JH, Jung H, Kim EH, Song IK, Kim HS, Kim JT. Optimal inspiratory pressure for face mask ventilation in paralyzed and unparalyzed children to prevent gastric insufflation: a prospective, randomized, non-blinded study. Can J Anaesth 2018; 65: 1288-1295.

7. Lee JH, Jung H, Jang YE, Kim EH, Song IK, Kim HS, et al. Manual vs pressure-controlled facemask ventilation during the induction of general anesthesia in children: A prospective randomized controlled study. Paediatr Anaesth 2019; 29: 331-337.

8. Bataille A, Rousset J, Marret E, Bonnet F. Ultrasonographic evaluation of gastric content during labour under epidural analgesia: a prospective cohort study. Br J Anaesth 2014; 112: 703-707.

9. Van de Putte P, Perlas A. Ultrasound assessment of gastric content and volume. Br J Anaesth 2014; 113: 12-22.

10. Qian X, Hu Q, Zhao H, Meng B, Nan Y, Cao H, et al. Determination of the optimal inspiratory pressure providing adequate ventilation while minimizing gastric insufflation using real-time ultrasonography in Chinese children: a prospective, randomized, double-blind study. BMC Anesthesiol 2017; 17: 126. 
11. Bouvet L, Albert ML, Augris C, Boselli E, Ecochard R, Rabilloud M, et al. Real-time detection of gastric insufflation related to facemask pressure-controlled ventilation using ultrasonography of the antrum and epigastric auscultation in nonparalyzed patients: a prospective, randomized, double-blind study. Anesthesiology 2014; 120: 326-334.

12. Park JH, Kim JY, Park K, Kil HK. A randomized comparison of volume- and pressure-controlled ventilation in children with the i-gel: Effects on peak inspiratory pressure, oropharyngeal leak pressure, and gastric insufflation. Medicine (Baltimore) 2017; 96: e6772.

13. Gautier N, Danklou J, Brichant JF, Lopez AM, Vandepitte C, Kuroda MM, et al. The effect of force applied to the left paratracheal oesophagus on air entry into the gastric antrum during positive-pressure ventilation using a facemask. Anaesthesia 2019; 74: 22-28.
14. Li C, Lu B, Meng B, Fan X, Wu G, Zhang Y, et al. [Effects of rocuronium on gastric insufflation related to facemask ventilation in general anaesthesia patients]. Zhonghua Yi Xue Za Zhi 2015; 95: 2616-2619.

15. Vasudevan A, Srinivasan S, Vinayagam S, Ramkumar G, Senthilnathan M. Assessment of effectiveness of cricoid pressure in preventing gastric insufflation during bag and mask ventilation: A randomized controlled trial. Saudi J Anaesth 2018; 12: 606-611.

16. Park JH, Kim JY, Lee JM, Kim YH, Jeong HW, Kil HK. Manual vs. pressure-controlled facemask ventilation for anesthetic induction in paralysed children: a randomized controlled trial. Acta Anaesthesiol Scand 2016; 60: 1075-1083.

\section{Statistics}

Excerpts from the Uniform Requirements for Manuscripts Submitted to Biomedical Journals updated November 2003.

Available from www.icmje.org

Describe statistical methods with enough detail to enable a knowledgeable reader with access to the original data to verify the reported results. When possible, quantify findings and present them with appropriate indicators of measurement error or uncertainty (such as confidence intervals). Avoid relying solely on statistical hypothesis testing, such as the use of $P$ values, which fails to convey important information about effect size. References for the design of the study and statistical methods should be to standard works when possible (with pages stated). Define statistical terms, abbreviations, and most symbols. Specify the computer software used. 